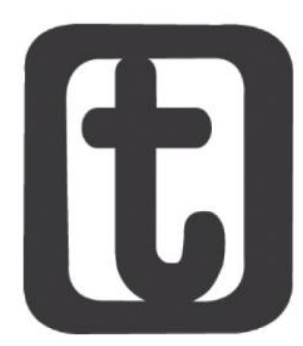

\title{
O EMPODERAMENTO DAS MULHERES E A LEI MARIA DA PENHA COMO TECNOLOGIA DE GÊNERO: POSSIBILIDADES COM OS ESTUDOS FEMINISTAS E DE GÊNERO PARA O SERVIÇO SOCIAL
}

The empowerment of women and the Maria da Penha law as technology of gender: possibilities with feminist and gender studies for social work

\section{Thiago F. Sant'Anna*}

RESUMO

Este artigo objetiva analisar a Lei no. 11.340/06, conhecida por Lei Maria da Penha, como uma tecnologia de gênero voltada para o enfrentamento de casos particulares de violência contra as mulheres, e para a transformação das relações de gênero e destruição da estrutura machista e misógina da sociedade. Compreendemos a violência contra as mulheres como uma das áreas de atuação de assistentes sociais por se tratar de uma das expressões questão social. A análise operada está ancorada no pensamento oriundo dos Estudos Feministas e de Gênero, no conhecimento do Serviço Social e no pensamento de Michel Foucault.

\section{PALAVRAS-CHAVE}

Gênero. Violência. Questão social. Serviço social. Lei Maria de Penha.

\section{ABSTRACT}

This article aims to analyze the Law 11.340/06, known as the Maria da Penha Law, as a technology of gender focused on coping with particular cases of violence against women, well as transforming gender relations and destroy the sexist and misogynistic structure of society. We understand violence against women as one of the areas of expertise of social workers because it is one of the expressions social issue. The analysis is anchored operated in thought coming from the Feminist Studies and Gender, from the knowledge of social work and the thought of Michel Foucault

\footnotetext{
* Historiador e Assistente Social. Doutor em História pela Universidade de Brasília (UnB). PósDoutorado em Arte e Cultura Visual (UFG). Professor dos cursos de graduação em Serviço Social e de Arquitetura e Urbanismo; e do Mestrado e Doutorado do Programa de Pós-Graduação em Arte e Cultura Visual da Universidade Federal de Goiás (UFG, Goiânia, Brasil). Av. Esperança, s/n, Chácaras de Recreio Samambaia, Goiânia (GO), CEP.: 74690-900. E-mail: <thiagof.santanna@yahoo.com.br>. ORC ID: <https://orcid.org/0000-0001-9197-668X>.
} 


\section{tempordilis}

SANT'ANNA, THIAGO F.

\section{KEYWORDS}

Gender. Violence. Social issues. Social work. Maria de Penha Law.

Submetido em: 28/4/2018.

Aceito em: 17/5/2018.

\section{A questão social e a performatividade do gênero}

Implacável não poderia deixar ser uma leitura sobre a Lei Maria da Penha ancorada na ótica dos Estudos Feministas e de Gênero, na busca por contribuir com reflexões no campo do conhecimento e provocar a intervenção dos assistentes sociais, haja vista que a Lei 11.340/06, de 7 de agosto de 2006, é, em nossa opinião, um poderoso instrumento não somente de coibição da violência contra as mulheres e punição para agressores, mas também de desestabilização da ordem patriarcal e misógina. ${ }^{1}$

Assunto incontornável, o problema da violência contra as mulheres tem sido uma questão social bastante expressiva. Isso porque esta forma de prática de violência integra o "[...] conjunto das expressões das desigualdades da sociedade capitalista madura" (IAMAMOTO, 2008, p. 27). Sob essa ótica, a experiência de violência sofrida por mulheres revela uma das "[...] múltiplas formas de pressão social, de invenção e de re-invenção da vida construídas no cotidiano, pois é no presente é que estão sendo recriadas formas novas de viver, que apontam um futuro que está sendo germinado" (IAMAMOTO, 2008, p. 28). Em alerta, preocupa-nos, diante disso, não somente a qualidade das ações adotadas pelo Estado e pela sociedade em geral, no sentido de conter tais práticas, mas também o equívoco em torno da construção da legitimidade social que a violência contra as mulheres tem ganhado em nossa sociedade, constituindo as práticas de violência contra as mulheres nas relações cotidianas patriarcais e misóginas enquanto experiências normalizadas e tomadas, em alguns casos, como "naturais".

As práticas de violência contra as mulheres, a sua legitimação e a sua naturalização, não podemos negar, são alimentadas por discursos que as tomam como naturais e normais. Já dizia Butler (2003) que o gênero "[...] é um laborioso processo de tornar-se 'naturalizado' [...]” (BUTLER, 2003, p. 107), cujo objetivo é “[...] mostrar que a idéia de [que] um corpo natural é um construto" (BUTLER, 2003, p. 181). Trata-se de efeitos das narrativas naturalizantes constituídas pelos dizeres do senso comum que perfazem estratégias voltadas para configurar corpos inscritos no âmbito da heterossexualidade e do patriarcalismo.

Continuando com a filósofa feminista, a naturalização das relações desiguais de gênero, baseadas na violência, são forjadas no âmbito da condição performativa do gênero. Segundo Butler (2001), a performatividade "[...] deve ser compreendida não como um 'ato' singular ou deliberado, mas, ao invés disso, como a prática

\footnotetext{
${ }^{1}$ Em relação ao termo misoginia: do grego miso = aversão; ginia $=$ mulheres. Em resumo, aversão às mulheres. Ver: Rago (2001). Em relação ao termo ordem patriarcal, compreendemos na acepção de Tânia Navarro Swain, para quem é um sistema em que o masculino "[...] se erige como norma e paradigma do humano [...]" (SWAIN, 2000, p. 55) e a mulher "[...] cuja existência se justifica pela sua capacidade de reprodução [...]" (SWAIN, 2000, p. 55).
} 
reiterativa e citacional pela qual o discurso produz os efeitos que ele nomeia [...]" (BUTLER, 2001, p. 154), o que, por sua vez, faz com que "[...] as normas regulatórias do 'sexo' trabalhem de uma forma performativa para constituir a materialidade dos corpos e, mais especificamente, para materializar a diferença sexual a serviço da consolidação do imperativo heterossexual” (BUTLER, 2001, p. 154). Enquanto “[...] uma reiteração de uma norma ou conjunto de normas [...]” (BUTLER, 2001, p. 167) pode ser reformulada da seguinte maneira:

(a) a performatividade de gênero não pode ser teorizada separadamente da prática forçosa e reiterativa dos regimes sexuais regulatórios; (b) a explicação da agência condicionada por aqueles próprios regimes de discurso/poder não pode ser confundida com o voluntarismo ou o individualismo, muito menos com 0 consumismo, e não pressupõe, de forma alguma, um sujeito que possa escolher; (c) o regime da heterossexualidade atua para circunscrever e contornar a "materialidade" do sexo e essa "materialidade" é formada e sustentada através de - e como uma materialização de normas regulatórias que são, em parte, aquelas da hegemonia sexual; (d) a materialização de normas exige aqueles processos identificatórios pelos quais as normas são assumidas ou apropriadas, e essas identificações precedem e possibilitam a formação de um sujeito, mas não são estritamente falando, executadas pelo sujeito; (e) os limites do construcionismo ficam expostos naquelas fronteiras da vida corporal onde corpos abjetos ou deslegitimados deixam de contar como "corpos". (BUTLER, 2001, p. 167)

Não há como não questionar, portanto, as inúmeras referências no cotidiano que, simbólica e materialmente, fomentam, dia-a-dia, a violência contra as mulheres. Tais narrativas naturalizantes, enquanto discursos, atuam performaticamente, produzindo, por meio do discurso, práticas de violência contra as mulheres. Isso porque, sendo performativo, o gênero está ancorado em regimes sexuais regulatórios, marcado pela hegemonia da heterossexualidade, ao mesmo tempo que delimita os espaços de atuação, livre, do sujeito. Sob essa ótica, o sujeito não tem outro caminho a não ser assumir ou apropriar-se dos processos identificatórios que este regime oferta, relegando os que vivem nas fronteiras e fora desses regimes à condição de objetos dessas narrativas naturalizantes, abjetos, isto é, nãocorpos. Nesse sentido, o mecanismo de produção da citação da lei através dessas máximas, enquanto "[...] mecanismo de sua produção e articulação" (BUTLER, 2001, p. 169), fortalece a reiteração e naturalização das normas regulatórias do sexo que são - ao invés de construídas - performativamente instituídas.

Mediante essa naturalização, uma operação de acobertamento do caráter socialmente construído e performativamente produtor destas práticas culturais é acionado através da reiteração de discursos/práticas que produzem a violência contra as mulheres no cotidiano da vida social. Neste caso, a violência contra as mulheres, enquanto uma questão social construída e equivocadamente tomada como "legítima" e "natural" em alguns casos, é constituída e constitutiva de discursos e práticas envolvidas neste conflito social. De tal modo, os conceitos de

Temporalis, Brasília (DF), ano 18, n. 35, jan./jun. 2018. 
questão social e performatividade, no que tange à investigação deste objeto em questão - a violência contra as mulheres - podem ser operados conjuntamente ao apreenderem a dimensão discursiva que, ao nomear, produz a questão social. ${ }^{2}$ Inspiramo-nos em lamamoto, para quem, suas palavras destacam a importância de abordagens criativas e não endógenas:

[...] é necessário romper com uma visão endógena, focalista, uma visão 'de dentro' do Serviço Social, prisioneira em seus muros internos. [...] Extrapolar o Serviço Social para melhor apreendê-lo na história da sociedade da qual ele é parte e expressão. [...] Um dos maiores desafios que o Assistente Social vive no presente é desenvolver sua capacidade de decifrar a realidade e construir propostas de trabalho criativas e capazes de preservar e efetivar direitos, a partir de demandas emergentes no cotidiano. Enfim, ser um profissional propositivo e não só executivo (IAMAMOTO, 2008, p. 20, grifo do autor)

Instiga-nos, nessa linha de reflexão criativa e não endógena, interpelar tal objeto de investigação - a Lei n. 11.340/06, conhecida como Lei Maria da Penha - a partir dos Estudos Feministas e de Gênero de matriz pós-estruturalista. Estas teorias feministas estão comprometidas com a elaboração de um projeto que implica "[...] tanto criticar as definições e representações existentes das mulheres como em criar novas imagens da subjetividade feminina" (BRAIDOTTI, 2000, p. 185). As teorias feministas pós-estruturalistas - que incluem as reflexões de Butler, Braidotti, Lauretis, Louro, neste texto operadas - perfazem, portanto, a elaboração de ferramentas analíticas poéticas, ricas e plurais, capazes de escapar aos hermetismos e blocos teóricos androcêntricos.

Daí ser possível afirmar que as/os assistentes sociais podem operar o arcabouço teórico-metodológico feminista, entrecruzado ao do Serviço Social, em suas experiências profissionais na busca por não somente acionar as práticas de atendimento às mulheres vítimas de violência, mas também a reunir forças para criticar e afrontar a produção de sentidos ancorados em um viés machista e misógino.

Ao seguirmos nessa direção, nos deparamos com a seguinte problemática: como assistentes sociais podem operar a Lei n. 11.340/06 como um discurso capaz de acionar e transformar práticas e experiências por meio das quais as pessoas homens e mulheres - podem tornar-se sujeitos em uma relação historicamente constituída comprometida com o combate à violência praticada pelos homens contra as mulheres? Que possibilidades o pensamento de Foucault (2002) acerca dos dispositivos de poder, combinado às abordagens feministas, podem suscitar

\footnotetext{
2 Em uma perspectiva deleuziana do conhecimento, adotamos um procedimento de desterritorialização dos conceitos, os quais são extraídos de sistemas de pensamento e dispostos em uma rede de relações com outros conceitos, advindos de outros sistemas de pensamento. Nesse sentido, articulamos uma passagem da perspectiva de lamamoto sobre o conceito de questão social e o abordamos junto ao conceito de performatividade de Butler, mesmo que, se observados enquanto dois sistemas de pensamento diferentes, Butler e lamamoto não combinam.
}

Temporalis, Brasília (DF), ano 18, n. 35, jan./jun. 2018. 
às/aos assistentes sociais no que se refere à possibilidade de operar de forma diferente a Lei 11.340/06 na busca por combater essa face das expressões da questão social?

Defender, intransigentemente, os direitos humanos e a recusa do arbítrio e do autoritarismo, defender o aprofundamento da democracia enquanto socialização da participação política e da riqueza socialmente produzida, empenhar-se para a eliminação de todas as formas de preconceito, incentivando o respeito à diversidade, à participação de grupos socialmente discriminados e à discussão das diferenças, bem como optar por um projeto profissional vinculado ao processo de construção de uma nova ordem societária, sem dominação, exploração de classe, etnia e gênero são palavras caras às/aos assistentes sociais no que tange ao exercício da sua profissão (CONSELHO FEDERAL DE SERVIÇO SOCIAL, 2012, p. 2224). Inseparáveis de suas práticas e experiências profissionais, bem como de seus saberes acumulados ao longo de anos, estas precisas palavras são capazes de deixar em alerta qualquer assistente social sensível à questão social da violência contra as mulheres no Brasil. São palavras, portanto, capazes de incentivar qualquer profissional do Serviço Social a buscar maneiras possíveis para enfrentar esse problema haja vista que o próprio art. 10, do "Capítulo III - Das Relações com Assistentes Sociais e outros/as Profissionais [...]” (CONSELHO FEDERAL DE SERVIÇO SOCIAL, 2012, p. 32), prevê enquanto deveres do/a assistente social, "[...] ser solidário/a com outros/as profissionais, sem, todavia, eximir-se de denunciar atos que contrariem os postulados éticos contidos neste Código [...]" (CONSELHO FEDERAL DE SERVIÇO SOCIAL, 2012, p. 32); e o art. 13 do "Capítulo IV - Das Relações com entidades da Categoria e demais organizações da Sociedade Civil", do mesmo capítulo, o qual também postula que é dever destes/as profissionais

[...] denunciar, no exercício da Profissão, às entidades de organização de categoria, às autoridades e aos órgãos competentes, casos de violação da Lei e dos Direitos Humanos, quanto a: corrupção, maus tratos, torturas, ausência de condições mínimas de sobrevivência, discriminação, preconceito, abuso de autoridade individual e institucional, qualquer forma de agressão ou falta de respeito à integridade física, social e mental do/a cidadão/cidadã. (CONSELHO FEDERAL DE SERVIÇO SOCIAL, 2012, p. 35).

Enquanto um discurso forjador de experiências possíveis voltadas para a constituição de sujeitos, comprometida com a autorização de identidades e construção de outras histórias possíveis, a Lei Maria de Penha, conhecida e operada por assistentes sociais, no interior das reflexões feministas foucaultianas, neste texto operadas, pode ser um poderoso instrumento tanto no combate aos casos de violência contra as mulheres quanto na desmontagem dos pilares da sociedade machista e misógina, a incluir nesta não somente as práticas e experiências, mas também os sentidos mobilizados nos discursos, nos preconceitos, nas narrativas naturalizantes que constituem as relações de gênero como hierarquicamente desiguais. 


\section{A Lei Maria da Penha como tecnologia de gênero}

Se a selvageria é uma condição constitutiva de muitas práticas de violência contra as mulheres, operadores do Direito e assistentes sociais não podem esquivar-se da condição múltipla e diferenciada contida nas diversas formas de expressão da violência contra as mulheres enquanto questão social. Que imagens da violência contra as mulheres, constitutivas da cena dentro do ambiente familiar e doméstico podem ser extraídas na lei? Longe de serem homogeneizantes, as práticas de violência contra as mulheres podem ser mapeadas já no $\S 2^{\circ}$. do art. $3^{\circ}$. do Título I, sobre as Disposições Preliminares da lei, onde reconhece-se que "[...] cabe à família, à sociedade e ao poder público criar as condições necessárias para o efetivo exercício dos direitos enunciados no caput" (BRASIL, 2006, não paginado). Tais considerações alinham aos detalhes que a lei descreve sobre a presença da violência ocorrida no âmbito doméstico no Título II Da Violência Doméstica e Familiar contra a Mullher. Ela dispõe, em seu art. $5^{\circ}$., as inúmeras formas de configuração deste tipo de violência como uma violação dos direitos humanos, independente da orientação sexual:

\footnotetext{
I - no âmbito da unidade doméstica, compreendida como o espaço de convívio permanente de pessoas, com ou sem vínculo familiar, inclusive as esporadicamente agregadas;

II - no âmbito da família, compreendida como a comunidade formada por indivíduos que são ou se consideram aparentados, unidos por laços naturais, por afinidade ou por vontade expressa;

III - em qualquer relação íntima de afeto, na qual o agressor conviva ou tenha convivido com a ofendida, independentemente de coabitação (BRASIL, 2006, não paginado).
}

A cena discursiva apresentada é construída pelas imagens das mulheres com seus parentes, pais, irmãos, filhos, maridos, namorados ou, até mesmo, amigos ou desconhecidos. O "ambiente doméstico", o “âmbito da família” ou "qualquer relação íntima de afeto" são construções que, apesar de tratadas de forma homogêneas, não escondem suas multiplicidades, pois são apresentadas conforme diversas nuances. Tais delimitações espaço-geográficas substanciam a idéia de que a noção de gênero emergente do texto da lei não está restrita à questão da mera diferença sexual, mas incorpora a construção sócio-cultural dos espaços onde as relações são travadas. Ser uma mulher vítima de uma brutal violência implica ser vítima do poder masculino, mas exige-nos um olhar por outras esferas do tecido social que nos apresenta outros personagens que, apesar de serem homens, são também parentes, pais, irmãos, filhos, maridos, namorados, amigos ou desconhecidos. São dimensões da identidade cujas posições independem da determinação natural do sexo, mas também abrangem laços de convivência, de parentesco ou não, sentimentos de pertencimento, exercícios da sexualidade, forma de convivência em geral.

Adentremos o espaço doméstico, os confins da instituição familiar, assegurada pelo escudo da sacralidade, aparentemente distante de selvageria, para encontrarmos, ao mesmo tempo, sua substância monstruosa e de terror que tem invadido a vida de muitas mulheres que visualizam, na vida após o casamento, a realização pessoal.

Temporalis, Brasília (DF), ano 18, n. 35, jan./jun. 2018. 


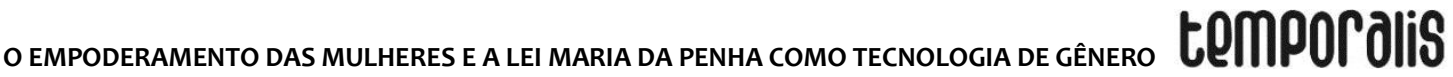

O alto índice de dados ${ }^{3}$, inegavelmente alarmantes, acerca da violência sofrida por mulheres no ambiente doméstico acena para a falência da instituição família enquanto lócus de proteção total das mulheres pelos homens. Pois é dentro da própria família e das relações afetivas que a envolvem que podemos localizar experiências de violência física, psicológica, sexual, patrimonial e moral às mulheres. E são, conforme o $\S 9^{\circ}$. do art. 129, os ascendentes, os descendentes, os irmãos, o conjugue ou companheiro, ou quem quer que conviva e estabeleça relações domésticas, de coabitação ou de hospitalidade, que são, normalmente, autores dos crimes (BRASIL, 2006). Diante disso, é tarefa incontornável às/aos assistentes sociais que lidam com mulheres vítimas de violência investigarem o que está por detrás do discurso dessas mulheres, enunciados nas instituições de proteção às vítimas, além de buscar, através dos seus instrumentos de trabalho, as raízes do problema.

Estas imagens da violência contra as mulheres nos remetem às condições de produção do exercício da violência contra as mulheres como oriunda de formação discursiva específica que definem "[...] aquilo que numa formação ideológica dada ou seja, a partir de uma posição dada em uma conjuntura sócio-histórica dada determina o que pode e deve ser dito" (ORLANDI, 2002, p. 43). Ou seja, a violência está inscrita em relações, práticas, comportamentos que englobam uma cultura patriarcal, machista e misógina, instituidoras da família como lócus de proteção feminina.

Nesta sociedade, a violência contra as mulheres dentro do ambiente doméstico tem como alvo privilegiado o corpo. Lesões, socos, pontapés, bofetões, violência carnal, atentado contra o pudor e ameaças perfazem uma variedade de técnicas brutais de apropriação e escrita da violência no corpo das mulheres pelos homens. Trata-se de um tipo de violência que atinge o corpo e alcança a alma, que ultrapassa os limites da raça, da idade ou da condição social com a diferença de que quando o fato ocorre com mulheres brancas, pertencentes às classes privilegiadas, toma proporções grandiosas em comparação com o descaso e o silêncio das cotidianas violências que mulheres negras e pobres sofrem diariamente.

Além destas condições de produção circunscritas social-espacialmente, elas também estão, segundo o art. $7^{\circ}$. , do Capítulo II Das Formas de Violência Doméstica e Familiar contra a Mulher, enumeradas entre as várias das formas de violências doméstica e familiar praticadas contra as mulheres como: violência física, psicológica, sexual, patrimonial e moral. As delimitações espaciais alimentam a pluralidade e a sofisticação de práticas discursivas que, no bojo do social atribuem e produzem sentidos às imagens da violência contra as mulheres. O cardápio não é pequeno, mas as possibilidades de escolha das formas de praticar a violência contra as mulheres atingem o corpo, alcança a alma, desbancam o patrimônio, deturpam o exercício da sexualidade e desmoralizam o sujeito feminino. Daí ser fundamental

\footnotetext{
${ }^{3}$ Segundo a Pesquisa Nacional por Amostras de Domicílios (PNAD), no site Portal Brasil, "[...] quatro em cada dez mulheres brasileiras já foram vítimas de violência doméstica [...]", perfazendo um total de $43,1 \%$ o número de mulheres que já foram vítimas de violência em sua própria residência ( $43 \%$ DE MULHERES..., 2011, não paginado).
} 
que assistentes sociais, no atendimento às vítimas de violência e no enfrentamento da sociedade machista e misógina que cria condições para o surgimento de práticas de violência contra as mulheres, percebam, no texto da lei Maria da Penha, o caráter múltiplo e disseminado destas práticas. Ao lançarem mão desta metodologia, tais profissionais podem perceber as nuances e condições de produção da violência.

Outra incursão sobre a leitura da lei n. 11.340/06 é o exercício que nos possibilita problematizar o conceito de "mulher" existente na lei, haja vista que inexiste essa condição universal e homogênea do gênero. Sob essa ótica, a interface da identidade de gênero com outras classificações identitárias possibilita-nos compreender a construção dos gêneros em nossa sociedade, perfazendo a interseccionalidade que articula a identidade de gênero às questões de classe, raça/etnia, geração, constituindo a multiplicidade do sujeito mulher. Como a lei em análise pode funcionar como tecnologia de gênero - na acepção dada por Lauretis (1994), qual seja, “[...] o conjunto de técnicas e estratégias discursivas por meio das quais o gênero é construído [...]” (LAURETIS, 1994, p. 204) - e, com efeito, produzir gêneros dentro e fora do modelo machista e misógino da sociedade? Daí, ao identificarmos o solo imaginário onde se inscreve a Lei n.11.340/06, a partir do qual emana imagens da violência contra as mulheres, podemos destacar outros direcionamentos possíveis e enxergar, no texto da lei, estratégias de subversão e superação do status quo. De vítimas e pessoas suscetíveis à violência, mulheres podem, ao conhecerem o dispositivo normativo em análise, ser empoderadas.

Para se transformar em uma tecnologia de gênero voltada para a mudança das relações de gênero em nossa sociedade - a transformação de mulheres frágeis em mulheres empoderadas -, a Lei Maria da Penha dispõe sobre as táticas e as estratégias discursivas voltadas para superação do quadro com as medidas integradas de prevenção, dispostas no art. $8^{\circ}$. do Capítulo I do Título III Da Assistência à Mulher em Situação de Violência Doméstica e Familiar como "[...] um conjunto articulado de ações da União, dos Estados, do Distrito Federal e dos Municípios" (BRASIL, 2006, não paginado). Esse conjunto articulado pode ser substanciado por meio da:

"[...] integração operacional do Poder Judiciário, do Ministério Público e da Defensoria Pública com as áreas de segurança pública, assistência social, saúde, educação, trabalho e habitação"; "promoção de estudos e pesquisas, estatísticas e outras informações relevantes, com a perspectiva de gênero e de raça ou etnia"; "respeito nos meios de comunicação social dos valores éticos e sociais da pessoa e da família, de forma coibir os papéis estereotipados que legitimem ou exacerbem a violência doméstica e familiar"; "implementação de atendimento policial especializado para as mulheres"; "promoção e a realização de campanhas educativas de prevenção da violência doméstica e familiar contra a mulher"; "celebração de convênios, protocolos, ajustes, termos ou outros instrumentos de promoção de parceria entre órgãos governamentais ou entre estes e entidades não governamentais"; "capacitação permanente das Polícias Civil e Militar, da Guarda Municipal, do Corpo de Bombeiros e dos profissionais pertencentes aos órgãos e às áreas enunciadas no inciso I quanto às questões de gênero e de raça ou etnia"; "destaque, nos

Temporalis, Brasília (DF), ano 18, n. 35, jan./jun. 2018. 
oEmposeranerro oas su

currículos escolares de todos os níveis de ensino, para os conteúdos relativos aos direitos humanos, à equidade de gênero e de raça ou etnia e ao problema da violência doméstica e familiar contra a mulher" (BRASIL, 2006, não paginado).

Além destas, a lei defende uma assistência à mulher de forma articulada e de acordo com os princípios e as diretrizes contidos na Lei Orgânica da Assistência Social, no Sistema Único de Saúde, no Sistema Único de Segurança Pública. Ou seja, a lei constitui uma rede de relações voltada para a coibição da violência, ao envolver juízes, policiais, intelectuais, imprensa, assistência social, políticos, professores. A rede de relações, a qual assistentes sociais não podem perder de vista, é estratégia da tecnologia de gênero, voltada para direcionar as práticas na contenção da violência contra as mulheres que, ao conhecerem o funcionamento desta rede profissional, são empoderadas para que possam desestabilizar pilares da sociedade machista e misógina que faz emergir a violência.

Tais estratégias sócio-discursivas possibilitadas pela Lei Maria da Penha para contribuir para a transformação das relações de gênero, instalam o mecanismo da "vigilância hierarquizada" por meio da qual se sofistica a fiscalização onde cada um fiscalizava uma parte. Vejamos como funciona a vigilância hierarquizada, segundo Foucault (2002, p. 148),

O poder na vigilância hierarquizada [...] funciona como uma máquina. [...] é o aparelho inteiro que produz 'poder' e distribui os indivíduos nesse campo permanente e contínuo. O que permite ao poder disciplinar ser absolutamente indiscreto, pois está em toda parte e sempre alerta, pois em princípio não deixa nenhuma parte às escuras e controla continuamente os mesmos que estão encarregados de controlar; e absolutamente 'discreto', pois funciona permanentemente e em grande parte em silêncio. A disciplina faz 'funcionar' um poder relacional que se auto-sustenta por seus próprios mecanismos e substitui o brilho das manifestações pelo jogo ininterrupto dos olhares calculados. Graças às técnicas de vigilância, a 'física' do poder, o domínio sobre o corpo se efetuam segundo as leis da ótica e de mecânica, segundo um jogo de espaços, de linhas, de telas, de feixes, de graus, e sem recurso, pelo menos em princípio, ao excesso, à força, à violência. Poder que é em aparência ainda menos 'corporal' por ser mais sabiamente 'físico' (FOUCAULT, 2002, p. 148).

Inscrita nas abordagens de Foucault acerca do conceito de "poder disciplinar", o mecanismo da "vigilância hierarquizada" possibilita que as/os assistentes sociais saibam operar juntamente com as instâncias que acionem técnicas e estratégias voltadas para coibir a violência contra as mulheres. Desprovidas/os de um poder que possa suprimir tais práticas de violência, pois não pode deter o poder como "uma coisa", as/os assistentes sociais podem vir a manusear a lei 11.340/06 como "uma máquina" e, a partir disso, "fazer "funcionar" um poder relacional" com os quais diversas instâncias do poder público possam ser acionadas e comprometidas com o enfrentamento de casos isolados e também de pilares da estrutura machista

Temporalis, Brasília (DF), ano 18, n. 35, jan./jun. 2018. 


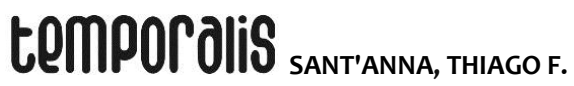

e misógina da sociedade. Estratégicas/os, as/os assistentes sociais precisam calcular, mensurar, conjeturar, presumir, na perspectiva de envolver não somente agressor e vítima, mas também envolver, conforme apontado anteriormente, juízes, policiais, intelectuais, imprensa, assistentes sociais, políticos, professores etc. O dispositivo da vigilância hierarquizada pode ser pensado, sob essa ótica, como um mecanismo de distribuição das responsabilidades, equacionamentos dos encargos, tanto no plano micro quanto macro.

Nesta experiência de contenção da violência contra as mulheres, o juiz, por exemplo, é personagem com tarefas definidas que, em seu art. 23, da Seção III "Das Medidas Protetivas de Urgência à Ofendida", deverá:

I - encaminhar a ofendida e seus dependentes a programa oficial ou comunitário de proteção ou de atendimento;

II - determinar a recondução da ofendida e a de seus dependentes ao respectivo domicílio, após afastamento do agressor;

III - determinar o afastamento da ofendida do lar, sem prejuízo dos direitos relativos a bens, guarda dos filhos e alimentos;

IV - determinar a separação de corpos; (BRASIL, 2006, não paginado).

Somando-se à responsabilidade do juiz, encontra-se a polícia que tem sua posição de autoridade substanciada pela lei. O Capítulo III Do Atendimento pela Autoridade Policial, do Título III Da Assistência à Mulher em Situação de Violência Doméstica e Familiar, prevê que, na hipótese da iminência ou da prática da violência doméstica e familiar contra a mulher, "[...] a autoridade policial que tomar conhecimento da ocorrência adotará, de imediato, as providências legais cabíveis [...]” (BRASIL, 2006, não paginado) como:

\footnotetext{
I - garantir proteção policial, quando necessário, comunicando de imediato ao Ministério Público e ao Poder Judiciário;

II - encaminhar a ofendida ao hospital ou posto de saúde e ao Instituto Médico Legal;

III - fornecer transporte para a ofendida e seus dependentes para abrigo ou local seguro, quando houver risco de vida;

IV - se necessário, acompanhar a ofendida para assegurar a retirada de seus pertences do local da ocorrência ou do domicílio familiar;

$V$ - informar à ofendida os direitos a ela conferidos nesta Lei e os serviços disponíveis (BRASIL, 2006, não paginado).
}

De porte da chamada para a sua ação, a autoridade policial, em casos de violência contra as mulheres, após a realização do registro da ocorrência, deverá adotar, de imediato, os procedimentos previstos no art. $12^{\circ}$., sem prejuízo daqueles previstos no Código do Processo Penal:

I - ouvir a ofendida, lavrar o boletim de ocorrência e tomar a representação a termo, se apresentada; 
II - colher todas as provas que servirem para o esclarecimento do fato e de suas circunstâncias;

III - remeter, no prazo de 48 (quarente e oito) horas, expediente apartado ao juiz com o pedido da ofendida, para a concessão de medidas protetivas de urgência;

IV - determinar que se proceda ao exame de corpo de delito da ofendida e requisitar outros exames periciais necessários;

$\mathrm{V}$ - ouvir o agressor e as testemunhas;

$\mathrm{VI}$ - ordenar a identificação do agressor e fazer juntar aos autos sua folha de antecedentes criminais, indicando a existência de mandado de prisão ou registro de outras ocorrências policiais contra ele;

VII - remeter, no prazo legal, os autos do inquérito policial ao juiz e ao Ministério Público (BRASIL, 2006, não paginado).

Podemos perceber que, na prática de acionar instâncias que possam se comprometer ao combate da violência contra as mulheres por meio da operação da lei, as/os assistentes sociais podem tomar a lei 11.340/06 como um dispositivo de poder estratégico com o qual os dados e informações colhidos, tanto da parte do agressor quanto da vítima, além dos registros documentados como boletim de ocorrência e exame de corpo de delito e, não se pode desprezar, os relatórios oriundos de prontuários, entrevistas e registros de observação construídos pelas/os assistentes sociais como peças e instrumentos valiosos para o enfrentamento de uma situação específica e para a formação de saber acerca do assunto violência contra as mulheres, com os quais, outros casos poderão ser apreciados analogamente. Daí serem fundamentais documentos como o termo redigido pela autoridade policial que, segundo o texto da lei, em seu parágrafo $1^{\circ}$. do art. $12^{\circ}$., prevê conter:

\footnotetext{
I - qualificação da ofendida e do agressor;

II - nome e idade dos dependentes;

III - descrição sucinta do fato e das medidas protetivas solicitadas pela ofendida (BRASIL, 2006, não paginado).
}

O saber construído acerca das práticas de violência contra as mulheres não pode ser desprezado no trajeto de enfrentamento dos acontecimentos singulares e dos padrões estruturais, pois, enquanto tecnologia de gênero, ele faz emergir outras representações de gênero, as quais possam tornar as mulheres mais empoderadas e menos indefesas e os homens, menos violentos e misóginos e mais filóginos (philos = amigo; gyne $=$ mulheres) $($ RAGO, 2001). Transformados em informação disseminada no seio da sociedade, tais saberes empoderam mulheres. 4

Tal saber acerca das práticas de violência contra as mulheres pode ser construído mediante documentos expressos nos parágrafos seguidos, $2^{\circ}$. e $3^{\circ}$., tais como:

$\S 2^{\circ}$. A autoridade policial deverá anexar ao documento referido no $\S 1^{\circ}$. o boletim de ocorrência e cópia de todos os documentos disponíveis em posse da ofendida.

\footnotetext{
4 Curiosamente, inúmeros sítios na internet utilizam a expressão “Maria da Penha neles!", como forma de demonstrar que, no senso comum, a lei pode funcionar como instrumento inibidor da violência.
} 
$\S 3^{\circ}$. Serão admitidos como meios de prova os laudos ou prontuários médicos fornecidos por hospitais e postos de saúde (BRASIL, 2006, não paginado).

O exame e a formação de um saber voltado para o enfrentamento de casos particulares, o empoderamento feminino e a desestabilização dos pilares da ordem patriarcal e misógina que atravessam as relações sociais podem emanar de exercícios de poder através dos vários envolvidos no processo, como as testemunhas e as próprias vítimas. Os policiais se inserem nesse mecanismo estratégico que faz a lei 11.340/06 ser uma tecnologia de gênero com a produção de documentos como o inquérito policial (art. 20) e os atos processuais (art. 21). Peça fundamental oriunda da documentação elaborada, o exame se torna um componente desta tecnologia que possibilitará a fabricação de novas representações de gênero ao longo do tempo, diluindo o exercício de poder masculino e empoderando mulheres.

Ao lado dos mecanismos da vigilância hierarquizada e do exame, a Lei Maria da Penha aciona também o elemento da sanção normalizadora. Segundo o texto da lei, no art. 17:

É vedada a aplicação, nos casos de violência doméstica e familiar contra a mulher, de penas de cesta básica ou outras de prestação pecuniária, bem como a substituição de pena que implique o pagamento isolado de multa (BRASIL, 2006, não paginado).

A sanção normalizadora, compreendida como uma peça no dispositivo de poder, funciona na redução do caráter repressivo do poder em prol do seu aspecto produtivo. Produtivo porque ao descrever, mesmo que formas de punição, elabora e fabrica práticas que agem no intuito de fecundar novas relações sociais, dentre elas, as de gênero. No art. 22 da lei (BRASIL, 2006), este caráter produtivo do poder por meio da sanção normalizadora pode funcionar na produção de práticas quando descreve que "[...] constatada a prática de violência doméstica e familiar contra a mulher, nos termos desta Lei, o juiz poderá aplicar, de imediato, ao agressor, em conjunto ou separadamente, as seguintes medidas protetivas de urgência, entre outras":

I - suspensão da posse ou restrição do porte de armas, comunicação ao órgão competente, nos termos da Lei no. 10.826, de 22 de dezembro de 2003;

II - afastamento do lar, domicílio ou local de convivência com a ofendida; III - proibição de determinadas condutas, entre as quais:

a) Aproximação da ofendida, de seus familiares e das testemunhas, fixando o limite mínimo de distância entre estes e o agressor;

b) Contato com a ofendida, seus familiares e testemunhas por qualquer meio de comunicação;

c) Frequentação de determinados lugares a fim de preservar a integridade física e psicológica da ofendida;

IV - restrição ou suspensão de visitas aos dependentes menores, ouvida a equipe de atendimento multidisciplinar ou serviço similar;

V - prestação de alimentos provisionais ou provisórios (BRASIL, 2006, não paginado). 


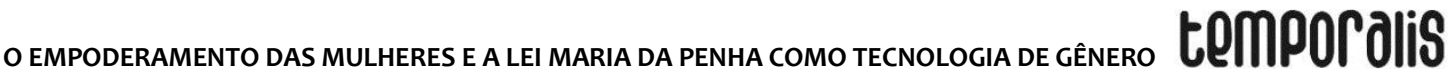

Ao invés de apenas reprimir, o dispositivo normativo produz condutas, fabrica comportamentos como o porte ilegal de armas, o afastamento do domicílio, o contato com a ofendida, além da restrição à visita aos dependentes, abalando práticas e exercícios de poder, tradicionalmente identificados ao mundo masculino, como o uso de armas, o poder patriarcal sobre a casa, a mulher e a linhagem.

Em outro momento, ao relatar as possibilidades de decisões do juiz, a lei dispõe sobre outras formas de atuação da sanção normalizadora que desestabilizam exercícios de poder masculinos, como o relativo ao patrimônio:

\footnotetext{
Art. 24. Para a proteção patrimonial dos bens da sociedade conjugal ou daqueles de propriedade particular da mulher, o juiz poderá determinar, liminarmente, as seguintes medidas, entre outras:

I - restituição de bens indevidamente subtraídos pelo agressor à ofendida;

II - proibição temporária para a celebração de atos e contratos de compra, venda e locação de propriedade em comum, salvo expressa autorização judicial;

III - suspensão das procurações conferidas pela ofendida ao agressor;

IV - prestação de caução provisória, mediante depósito judicial, por perdas e danos materiais decorrentes da prática de violência doméstica e familiar contra a ofendida (BRASIL, 2006, não paginado).
}

O dispositivo da sanção normalizadora operado na lei 11.340/06, não há como duvidar, empodera mulheres e desempodera homens quando o assunto é violência de gênero, pois perfaz um aparelho tecnológico de construção de gêneros, ancorado na atribuição de tarefas às próprias instituições, como o faz com o Ministério Público, o qual caberá:

\footnotetext{
I - requisitar força policial e serviços públicos de saúde, de educação, de assistência social e de segurança, entre outros;

II - fiscalizar os estabelecimentos públicos e particulares de atendimento à mulher em situação de violência doméstica e familiar, e adotar, de imediato, as medidas administrativas ou judiciais cabíveis no tocante a quaisquer irregularidades constatadas;

III - cadastrar os casos de violência doméstica e familiar contra a mulher (BRASIL, 2006, não paginado).
}

Longe de ser apenas uma lei a ficar no papel, a conhecida Lei Maria da Penha, em homenagem à mulher homônima que sofreu agressões do marido durante anos, pode não somente servir de normativa voltada para fazer operar os mecanismos de combate à violência em casos particulares, mas, enquanto uma tecnologia de gênero, estabelece uma nova política de espaço no enfrentamento da violência contra as mulheres ao estabelecer compromissos a serem assumidos pelas diversas instâncias da Federação, ao legislar, julgar e executar com base em direitos e deveres que garantem às mulheres uma vida livre de violência, como prevê nas suas Disposições Finais, em específico o art. 35, que estabelece:

Art. 35. A União, o Distrito Federal, os Estados e os Municípios poderão criar e promover, no limite das respectivas competências: 


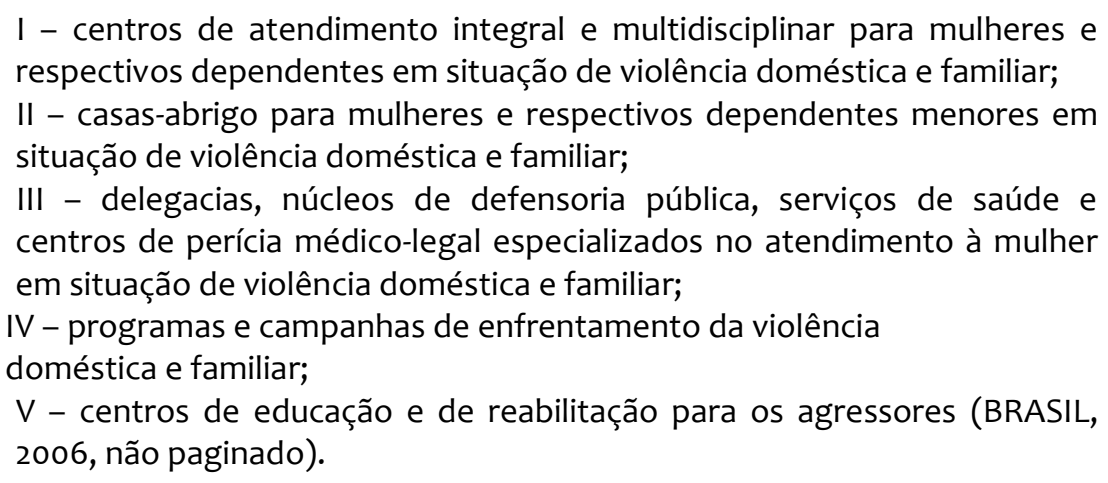

Além de enfrentar casos particulares, empoderar as mulheres e buscar destruir as práticas sociais que são constituídas e constituintes da ordem patriarcal e misógina que preside as relações sociais a Lei 11.340/06 é implacável no fortalecimento e na construção de uma nova ordem político-social com estratégias que garantirão, no futuro, uma redução significativa dos números da violência doméstica de familiar no Brasil. Centros de Atendimento, Casas de Abrigo, Delegacias, Programas e Campanhas, além dos Centros de Educação e Reabilitação para os Agressores, locais de atuação de assistentes sociais, vislumbram, ao dar efetividade às possibilidade da lei em criar, performativamente, outras relações de gênero, tornando-as/os protagonistas de um trabalho voltado para suprimir essa mancha na história do Brasil.

É sob essas argumentações que buscamos sustentar a compreensão de que com a Lei 11.340/06, conhecida como Lei Maria da Penha - tomada aqui como uma tecnologia de gênero, ou seja, como uma "[...] técnica e estratégia discursiva por meio das quais o gênero é construído [...]" (LAURETIS, 1994, p. 204) - as mulheres podem estar, estrategicamente, melhor posicionadas nas relações sociais de gênero - que são historicamente desiguais - ao poderem contar com um dispositivo normativo que às protegem e punem homens agressores. Empoderadas aqui significa terem condições de efetivar uma experiência com seus direitos e deveres garantidos por leis do Estado de Direito, capazes de possibilitar a elas uma vida digna. Assistentes sociais, ao orientar mulheres sejam vítimas ou não de violência na garantia de seus direitos a uma vida livre de violência, ao militar em movimentos sociais marcados pela abordagem de gênero, bem como ao realizar estudos e pesquisas voltados para esses assuntos, podem muito contribuir nesse processo de empoderamento das mulheres compreendido como um processo ancorado na promoção dos princípios do seus Código de Ética como a contribuição para a defesa dos direitos humanos, para a ampliação e consolidação da cidadania, para a defesa do aprofundamento da democracia, para o posicionamento em favor da equidade e justiça social e para o empenho na eliminação de formas de preconceito (CONSELHO FEDERAL DE SERVIÇO SOCIAL, 2012). Ao atuarem na garantir de um direito a uma vida livre de violência, assistentes sociais podem contribuir para a redução da condição de vulnerabilidade das pessoas, sejam frutos da contradição capital $X$ trabalho, sejam frutos de outras formas de produção de desigualdade, como as de gênero. 


\section{Referências}

43\% DAS MULHERES já foram vítimas de violência doméstica, segundo anunário.

Agência Brasil, Brasília (DF), 5 jul. 2011. Disponível em: <http://www.brasil.gov.br/governo/2011/07/43-das-mulheres-ja-foram-vitimas-deviolencia-domestica-segundo-anuario >. Acesso em: 10 fev. 2014.

BRAIDOTTI, Rosi. Sujetos nómades: corporización y diferencia sexual en la teoria feminista contemporânea. Buenos Aires; Barcelon; México: Paidós, 2000.

BRASIL. Presidência da República. Lei n 11.340/06, de 7 de agosto de 2006. Cria mecanismos para coibir a violência doméstica e familiar contra a mulher, nos termos do $\S 8^{\circ}$ do art. 226 da Constituição Federal, da Convenção sobre a Eliminação de Todas as Formas de Discriminação contra as Mulheres e da Convenção Interamericana para Prevenir, Punir e Erradicar a Violência contra a Mulher; dispõe sobre a criação dos Juizados de Violência Doméstica e Familiar contra a Mulher; altera o Código de Processo Penal, o Código Penal e a Lei de Execução Penal; e dá outras providências. Brasília (DF), 2006. Disponível em: <http://www.planalto.gov.br/ccivil_03/_ato2004-2006/2006/lei//11340.htm>. Acesso em: 22 de set. 2010.

BUTLER, Judith. Problemas de gênero: feminismo e subversão da identidade. Rio de Janeiro: Civilização Brasileira, 2003.

BUTLER, Judith. Corpos que pesam: sobre os limites discursivos do "sexo". In: LOURO, Guacira (Org.). O corpo educado: pedagogias da sexualidade. 2. ed. Belo Horizonte: Autêntica, 2001. p. 151-176.

CONSELHO FEDERAL DE SERVIÇO SOCIAL. Código de Ética do/a Assistente Social. 10. ed. Brasília (DF), 2012.

FOUCAULT, Michel. Vigiar e punir: nascimento da prisão. 25. ed. Petrópolis: Vozes, 2002.

IAMAMOTO, Marilda. O Serviço Social na contemporaneidade: trabalho e formação profissional. 15. ed. São Paulo: Cortez, 2008.

LAURETIS, Teresa. Tecnologias do Gênero. In: HOLLANDA, Heloísa (Org.). Tendências e impasses: o feminismo como crítica da cultura. Rio de Janeiro: Rocco, 1994.

ORLANDI, Eni. Análise de discurso: princípios e procedimentos. 4. ed. Campinas: Pontes, 2002. p. 43.

RAGO, Margareth. Feminizar é preciso ou por uma cultura filógina. São Paulo em Perspectiva, São Paulo, v. 15, n. 3, p. 53-66, 2001. Disponível em:

<http://www.scielo.br/pdf/spp/v15n3/a09v15n3.pdf>. Acesso em: 15 jun. 2003. 


\section{tempor OliS santranu, truaco:}

SWAIN, Tania Navarro. "A invenção do corpo feminino ou a hora e a vez do nomadismo identitário". Textos de História, Brasília (DF): UnB, v. 8, n. 1

(Feminismos: Teorias e Perspectivas. Número organizado por Tânia Navarro Swain), p. 47-85, 2000. 